\title{
Wstęp: plakat jako narzędzie propagandy wojennej
}

Każda władza państwowa, niezależnie od szerokości geograficznej, ideologii oraz ustroju, od zawsze zainteresowana była wykorzystaniem najnowocześniejszych i najskuteczniejszych $\mathrm{w}$ danym czasie narzędzi wpływu społecznego. Narzędzia te ewoluowały wraz ze zmieniającymi się stylami społecznego zarządzania, ale i na skutek technologicznego postępu, szczególnie zaś rozwoju środków masowej komunikacji. Wraz $\mathrm{z}$ udoskonaleniem technik kolorowego druku pod koniec wieku XIX i na początku wieku XX rozwinęła się w nieznanym do tej pory stopniu produkcja plakatów ${ }^{1}$. Bardzo szybko stały się one głównym nośnikiem rozmaitego typu przekazów o zasięgu masowym. O sukcesie tego medium przesądziły niskie koszty i szybkość produkcji, możliwości eksponowania plakatów $\mathrm{w}$ dowolnej przestrzeni publicznej oraz to, że można było je reprodukować w prasie, dodatkowo zwiększając zasięg ich oddziaływania. Nie dziwi zatem fakt, że podczas I wojny światowej wszyscy uczestnicy konfliktu sięgnęli po ów sprawdzony już, popularny i skuteczny przekaźnik. Od tego momentu plakat stał się nieodzownym elementem wojennej propagandy. Środki perswazji stosowane w reklamie wizualnej zaczęto wykorzystywać do sterowania nastrojami społecznymi. Zachęcano obywateli do wojennego wysiłku, do pracy na rzecz przemysłu zbrojeniowego, przypominano o konieczności oszczędzania i zachowania strategicznych informacji, wreszcie wskazywano wroga.

\footnotetext{
${ }^{1}$ Najstarszy znany dziś plakat pochodzi ze średniowiecza i został zamówiony przez biskupa Paryża w roku 1482. Zapowiadał misteria wielkanocne wystawiane przed katedrą Notre Dame (Lisowska-Magdziarz 2009: 17). Jednak dopiero wiek XVII rozpoczyna erę wielkiej popularności tego medium.
} 
Oddajemy do Państwa rąk monografię, w której przyglądamy się plakatom wojennym, usytuowanym $\mathrm{w}$ różnych kontekstach historycznych i społecznych. Nasza uwaga zogniskowała się przede wszystkim na ich funkcji propagandowej, ale nie można analizować jej bez uwzględnienia aspektów estetycznych, ideologicznych czy psychologicznych. Ograniczenie naszych rozważań do plakatu dało szansę nie tylko monograficznego ujęcia problematyki badawczej, lecz także stworzyło możliwość rozpoznania plakatu jako narzędzia manipulacji z perspektywy wielu dekad.

Warto także nadmienić, że plakat, ze względu na swoją formę, a w związku z tym także zadania, jakie przed nim stawiano, był wszechobecny w życiu jednostki, która poddana jego wpływowi, włączała go do swojego codziennego świata, nierzadko w sposób bezrefleksyjny. „Afisze i plakaty spostrzegane są nawet przez tych przechodniów, którzy się śpieszą. Poprzez multiplikowanie ogłoszeń, są poddawani ich wpływowi w stopniu daleko większym niż by się wydawało" (Golka 1994: 60). Plakat stał się częścią wyreżyserowanej relacji pomiędzy państwem a obywatelem, zaszczepiając u tego ostatniego określoną wizję świata promowaną przez państwo. W przypadku plakatu wpływ ten miał dwie zasadnicze cechy, mianowicie egalitaryzował obywateli, którzy bez względu na swoją sytuację materialną byli odbiorcami treści propagandowych, gdyż nie musieli ponosić żadnych wydatków, jak choćby w przypadku zakupu prasy, biletu do kina czy odbiornika radiowego lub później telewizyjnego. Po drugie zaś, forma plakatu dawała możliwość konstruowania takich przekazów, które były czytelne dla wszystkich odbiorców, niezależnie od stopnia ich wykształcenia i możliwości percepcyjnych. Obraz łatwiej jest przyswoić i zapamiętać niż wypowiedź ustną bądź pisemną. Ludzie wielokrotnie nie pamiętają treści pisanych, umieszczonych na plakatach, potrafią za to dokładnie opisać „co na nim jest". Zależność ta świadczy o sile oddziaływania plakatu, który, przedkładając obraz nad słowo pisane, wnika w świadomość odbiorcy, pozostając w niej na długo. Tym samym traktujemy badanie plakatu jako próbę dotarcia do matrycy wszystkich późniejszych form wizualnej propagandy.

Należy także zauważyć, że choć treści plakatu zazwyczaj są dość proste $\mathrm{w}$ odbiorze, to jednak, by osiągnąć efekt „przejrzystości” oraz skuteczności, pracy nad nim podejmowali się specjaliści z różnych dziedzin. Władze wielu państw powoływały w tym celu instytucje, których zadaniem było opracowywanie formy i treści mających trafić do odbiorców w sposób najbardziej efektywny. Instytucje te często współpracowały ze 
środowiskami artystycznymi, powstające plakaty niejednokrotnie nosiły zaś znamiona dzieł sztuki, czego przykłady znaleźć można w niniejszej monografii. Nadrzędne przeznaczenie plakatu, jakim było wywarcie wpływu i skłonienie do pożądanego zachowania wśród odbiorców, pozostaje niezmienne. Do osiągnięcia tego celu wykorzystywano szereg zabiegów stylistycznych i graficznych, takich jak gra kolorów, zastosowanie sugerującej odbiór perspektywy, a także w określony sposób odzwierciedlano charakter postaci przedstawianych na plakacie. Niektóre z nich miały straszyć, przerażać, budzić odrazę, inne wzbudzać litość, wstyd lub nadzieję. Twórcy plakatu koncentrowali się na fizjonomii przedstawianej sylwetki bohatera, jego stroju, mimice, wykonywanym geście. Istotne były rekwizyty i otoczenie bohaterów przedstawień. Całość musiała uzupełniać się nawzajem, tworząc spójny, jednoznaczny i łatwy do odczytania przekaz. Czynnikiem wspólnym dla wszystkich plakatów jest wyrazistość przekazu i maksymalne ograniczenie marginesu dowolności interpretacyjnej. Odbiorca posteru ma go postrzegać w sposób zgodny z intencjami jego nadawcy. Wyrazistość plakatu objawia się także $w$ manichejskiej wizji świata. Plakat jasno precyzuje, co jest dobre, a co złe, w związku z czym prezentowane treści mają charakter biegunowy, jaskrawy, groteskowy, bez przestrzeni, którą odbiorca mógłby zrozumieć opacznie, to znaczy niezgodnie z zamierzeniami twórcy plakatu. "Strumień myśli" i skojarzeń wywołanych przez plakat u odbiorców nie może „meandrować", lecz musi podążać wcześniej zaprojektowanym przez nadawców kanałem interpretacji. Tylko wtedy plakat propagandowy jest skuteczny i ten czynnik różni go zasadniczo od innych jego zastosowań. Poznanie technik kreowania skutecznego przekazu propagandowego stało się naszym celem i zmusiło do refleksji nad metodą badania komunikatów wizualnych. Dlatego też ambicją inicjatorów niniejszego tomu było, między innymi, ukazanie różnorakich sposobów dociekania sensów i znaczeń analizowanych obrazów. Jest to o tyle trudne, że plakat propagandowy jest tekstem kultury i komunikatem silnie zakorzenionym w określonym kontekście historycznym. Nie dziwi więc, że autorzy składających się na tę książkę szkiców musieli okazać i okazali wyczulenie na ów kontekst. Niektórzy perspektywę historyczną uczynili główną osią narracji i silnie uwypuklonym kryterium objaśniającym (np. M. Melnyk, P. Chomczyński, M. Forc), dla innych zaś „,historia” była znaczącym punktem odniesienia. Przede wszystkim jednak są to analizy socjologiczne. Każdy z autorów posłużył się wybrana, zazwyczaj bliską sobie poprzez nabyte wcześniej doświadczenie, metodą badawczą. 
Otwierający niniejszą monografię tekst "Hej! Kto Polak na bagnety" kontra "Obronimy zdobycze Października". Polskie i radzieckie plakaty wojenne próba zrozumienia, autorstwa Waldemara Dymarczyka, stanowi (wciąż jeszcze stosunkowo rzadki na rodzimym gruncie) przykład użycia metodologii teorii ugruntowanej w odniesieniu do danych wizualnych. Badacz szczególną uwagę poświęcił problemowi adekwatnego opisu i kodowania zebranego materiału. Dlatego też oprócz standardowych procedur kodowania, posłużył się również takimi, które są dedykowane na użytek analizy obrazów. Chodzi o zaproponowane przez Krzysztofa Koneckiego (2008) „rodziny kodowania” oraz tzw. big picture, specification $i$ locating memo autorstwa Adele Clarke (2005).

Autorka drugiego z tekstów, Magdalena Melnyk (Obraz hiszpańskiej wojny domowej na plakatach), zaproponowała esej z wykorzystaniem elementów analizy treści oraz wprowadzającym szkicem historycznym. Jej tekst ma także charakter analizy porównawczej, ujawniając to, co różne oraz to, co wspólne na hiszpańskich plakatach. Autorka ukazuje interesujący zabieg stosowany przez obie strony konfliktu, polegający na maskowaniu tego, że wrogiem $\mathrm{w}$ istocie był rodak. Bratobójcza walka ukazana została na plakatach jako starcie faszysty z komunista, kapitalisty $\mathrm{z}$ robotnikiem, katolika z niewiernym.

Indukcyjne podejście w stosunku do analizy materiałów wizualnych zaproponował Piotr Chomczyński w tekście pt. „Wielka wojna ojczyźniana" na plakatach sowieckich. Choć autor wspomina, że pewną inspirację stanowiły dla niego prace, w których użyto analizy treści (Rose 2007; Ferenc 2007), to jednak zdecydował się generować kategorie analityczne i ich własności, korzystając $\mathrm{z}$ metodologii teorii ugruntowanej w tradycyjnej, modernistycznej wersji (Strauss i Corbin 1990). Chomczyński zwrócił przy tym baczną uwagę na kontekst czasowy powstania opisywanych dzieł propagandowych. Uwzględnienie owego kontekstu pozwoliło poczynić kilka ciekawych uwag odnoszących się do socjotechniki wykorzystywania plakatu w konkretnych sytuacjach wojennych.

Kamilla Biskupska, autorka rozdziału pt. Analiza dyskursywna amerykańskich plakatów rekrutacyjnych okresu II wojny światowej, podjęła się zadania opisania zebranych danych wizualnych z punktu widzenia badacza zainteresowanego rodzajem analizy wskazanej w tytule. Wychodząc od klasycznych ujęć (de Saussure, Peirce), poszukiwała adekwatnego sposobu zastosowania perspektywy dyskursywnej w odniesieniu do materiałów wizualnych. Interesujących inspiracji dostarczyły między innymi 
metodologiczne uwagi G. Rose (2007) i „kolorystyczne” sugestie B. Bergströma (2009). To właśnie analiza „barw walki” stanowi o oryginalności tego szkicu.

Tekst Bohater, wróg, zdrajca - amerykańskie i niemieckie plakaty z okresu II wojny światowej autorstwa Tomasza Ferenca, to przykład zastosowania explicite analizy treści (por. Ogryzko-Wiewiórkowski 1984) wzbogaconej komentarzami odnoszącymi się do kontekstu historycznego, politycznego oraz założonego, propagandowego, wydźwięku obrazów. Wygenerowane kategorie (płci, wieku, rasy, przywództwa, symboliki, sposobów ukazywania "siebie" i wroga, metod łączenia obrazu i tekstu, stereotypów i kolorystyki) są pretekstem do szerszych rozważań na temat ich możliwych użyć.

$\mathrm{Z}$ podobnym podejściem mamy do czynienia $\mathrm{w}$ przypadku rozdziału autorstwa Marty Forc. Badaczka, zainspirowana pracą Tomasza Ferenca, zastosowała zaproponowany przez niego sposób analizy. Podobne kategorie, lecz niepodobny kontekst analizowanych zdarzeń („,wojna po wojnie") implikował oryginalne podejście do zagadnień historycznych i politycznych oraz propagandowych. Autorka ukazała między innymi swoiste "zapętlenie" walki i propagandy w zmilitaryzowanym, komunistycznym społeczeństwie.

Niniejszy tom w pewnym sensie podsumowuje szkic Anny Matuchniak-Krasuskiej pod tytułem Między groteska a realizmem. O estetycznej stylizacji plakatów. Autorka poddała analizie zamieszczone w tomie plakaty, koncentrując się na ich aspekcie formalno-estetycznym. Tekst w warstwie treściowej i metodologicznej lokuje się w obszarze eksploracji charakterystycznym dla socjologii sztuki. Autorka, korzystając ze swego wieloletniego doświadczenia badawczego (Matuchniak-Krasuska 1999; 2006) oraz odwołań do obszernej literatury przedmiotu, przeanalizowała zebrane dzieła $\mathrm{w}$ kontekście zastosowania przez twórców plakatów określonych stylistyk plastycznych. Chodzi mianowicie o odpowiedź na pytanie: kiedy i dlaczego postaci obecne na obrazach propagandowych przybierają realistyczne bądź groteskowe formy (w różnych odmianach). Ponadto autorka rozważa przyczyny stosowania takich a nie innych środków wyrazu oraz zastanawia się nad tym, jaki efekt propagandowy mogą wywierać owe środki. Tekst ten stał się zatem swoistym podsumowaniem całego tomu, ale zarazem formą $\mathrm{w}$ znacznym stopniu eksperymentalną. Praca nad materiałem wizualnym, wykorzystanym już przez autorów uprzednich tekstów, pokazała, jak zmiana perspektywy badawczej doprowadza do nowych odkryć. 
Książkę zamyka tekst autorstwa Eweliny Wejbert-Wąsiewicz analizującej to, w jaki sposób twórcy wojennych plakatów wykorzystywali na nich wizerunki kobiet. Szkic ten dodaje nową perspektywę, spojrzenie feministyczne, wzbogacając niewątpliwie niniejszą publikację.

Zapraszając do lektury omawianego tomu, mamy nadzieję, że zarówno pod względem analitycznym, jak i metodologicznym będzie stanowił on wkład w socjologiczną tradycję badania propagandy.

Pragniemy podziękować Panu Dziekanowi Wydziału Ekonomiczno-Socjologicznego Uniwersytetu Łódzkiego, prof. zw. dr. hab. Janowi Gajdzie, za cenne wskazówki, wsparcie i wiarę w powodzenie naszej pracy.

Pragniemy także złożyć podziękowania Fundacji Uniwersytetu Łódzkiego, bez której pomocy nie udałoby się nam wydać niniejszej monografii.

Słowa podziękowania kierujemy również pod adresem dyrekcji i pracowników Muzeum Niepodległości w Warszawie, Muzeum Wojska Polskiego w Warszawie i Muzeum Tradycji Niepodległościowych w Łodzi za udostępnienie zbiorów i pomoc w poszukiwaniach plakatów.

Ponadto chcielibyśmy wyrazić podziękowania wszystkim osobom, które swoim zaangażowaniem, pomoca, radą i umiejętnością rozwiązywania problemów przyczyniły się do powstania tej publikacji.

\section{Tomasz Ferenc, Waldemar Dymarczyk, Piotr Chomczyński}

\section{Bibliografia}

Bergström, B., (2009), Komunikacja wizualna. Warszawa: Wydawnictwo Naukowe PWN.

Clarke, A. E., (2005), Situational Analysis. Grounded Theory After the Postmodern Turn. Thousand Oaks, CA: Sage.

Ferenc, T., (2007), Analiza obrazów - przeglad metod i inspiracji teoretycznych, „Acta Universitatis Lodziensis. Folia Sociologica", 32, 27: 5-26.

Golka, M., (1994), Świat reklamy. Warszawa: Agencja Badawczo-Promocyjna ARTIA.

Konecki, K. T., (2008), Wizualna teoria ugruntowana. Rodziny kodowania wykorzystywane w analizie wizualnej, „Przegląd Socjologii Jakościowej”, t. 4, nr 3 http://www.qualitati vesociologyreview.org/PL/archive_pl.php [data dostępu: 11.2010]

Lisowska-Magdziarz, M., (2009), Reklama na świecie, [w:] Wiedza o reklamie. Od pomystu do efektu. Bielsko-Biała: ParkEdukacja. 
Matuchniak-Krasuska, A., (1999), O recepcji groteski J. Dudy-Gracza. Łódź: Wydawnictwo Uniwersytetu Łódzkiego.

Matuchniak-Krasuska, A., (2006), Poza obiegami - społeczne funkcjonowanie groteski, „Przegląd Socjologiczny", t. 55, $\mathrm{nr}$ 2: 43-64.

Ogryzko-Wiewiórkowski, H., (1984), Zastosowanie analizy treści w badaniach socjologicznych, „Annales Universitatis Mariae Curie-Skłodowska”, vol. IX, nr 1.

Rose, G., (2007), Visual Methodologies. An Introduction to the Interpretation of Visual Materials. Los Angeles-London-New Delhi-Singapore: Sage.

Strauss, A. L., Corbin, J., (1990), Basics of Qualitative Research. Grounded Theory. Procedures and Techniques. California: SAGE Publications.

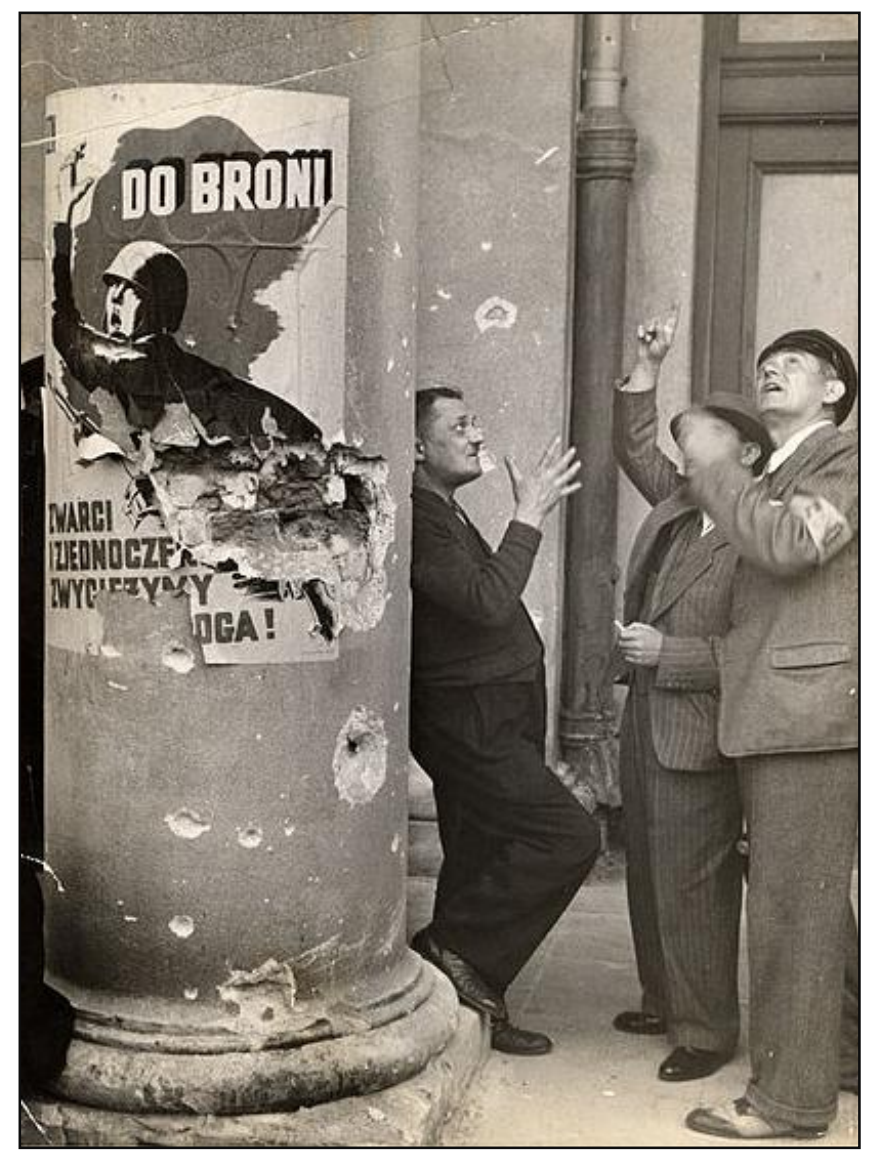

Fot. Julien Bryan

zdjęcie ze zbiorów Muzeum Holocaustu w Waszyngtonie 